\section{Differences in PTSD Symp- tomatology Among Latinos with Childhood and Adult Trauma: The Moderating Effect of Acculturation}

Julia A DiGangi ${ }^{1}$, Andrea J Goddard ${ }^{3}$, Steven A Miller ${ }^{4}$ Gabriela Leon ${ }^{2}$ and Leonard A Jason ${ }^{2 *}$

${ }^{1}$ VA Boston Healthcare System, Harvard Medical School, Boston, USA

${ }^{2}$ Center for Community Research, DePaul University, Chicago, Illinois, USA

${ }^{3}$ Clinical Psychology, The Adler School of Professional Psychology, Chicago, Illinois, USA

${ }^{4}$ Department of Psychology, Rosalind Franklin University of Medicine and Science, North Chicago, Illinois, USA

\begin{abstract}
The development of PTSD has been shown to be dependent on a variety of factors, including ethnicity, whether the trauma was experienced as a child or adult, and degree of acculturation. Using 104 Latinos who had completed treatment for substance abuse disorder(s), this study compared PTSD symptomatology for individuals reporting their Worst Traumatic Event (WTE) in childhood versus adulthood. The moderating effect of acculturation was also examined. Although many studies have reported on the pernicious effects of childhood trauma, very few have provided direct comparisons of child and adult trauma in terms of PTSD symptoms. Results indicated that those reporting their WTE in childhood had greater PTSD symptomatology than those reporting in adulthood. Acculturation moderated the relationship between timing of the trauma and PTSD symptoms. Specifically, those who reported their WTE in childhood and had the lower levels of acculturation, reported the higher number of PTSD symptoms. Implications and future directions are discussed.
\end{abstract}

Keywords: Acculturation; Adulthood trauma; Childhood trauma; Cumulative stress; Latinos; Posttraumatic stress disorder

PTSD is a psychiatric condition marked by a failure to recover from initial symptoms associated with trauma exposure. PTSD symptoms

*Corresponding author: Leonard A Jason, Center for Community Research, DePaul University, Chicago, Illinois, USA, Tel: +1 7733252018; E-mail: jason@ depaul.edu

Citation: DiGangi JA, Goddard AJ, Miller SA, Leon G, Jason LA (2016) Differences in PTSD Symptomatology Among Latinos with Childhood and Adult Trauma: The Moderating Effect of Acculturation. J Addict Addictv Disord 3: 009

Received: November 19, 2015; Accepted: December 21, 2015; Published: January 07, 2016

Copyright: (c) 2016 DiGangi JA, et al., This is an open-access article distributed under the terms of the Creative Commons Attribution License, which permits unrestricted use, distribution, and reproduction in any medium, provided the original author and source are credited. include re-experiencing the traumatic event (e.g., flashbacks), avoidance and numbing (e.g., blunted affect, avoidance of trauma-related stimuli), and hyperarousal (e.g., exaggerated startle response; American Psychiatric Association, 2000). While PTSD is a diagnosis that has been documented across cultures, there is considerable evidence that demonstrates that the expression of PTSD is culture dependent [1-5].

In the case of Latinos, now the largest minority in the USA, research suggests that Latinos may be at higher risk for both the traumas that lead to PTSD [6-9] and PTSD itself [10-13]. Although it appears that while the lifetime prevalence of PTSD among Latinos does not typically differ from their white and black counterparts [14], Latinos do appear to be at greater risk for PTSD in samples of Vietnam veterans $[11,15]$.

Ample evidence has indicated that the timing of when trauma occurs on the developmental continuum (i.e., childhood vs. adulthood) can affect both the development of PTSD and its subsequent symptomatology in adulthood. The few studies that have compared the impact of adult versus childhood trauma found that child trauma leads to more severe symptomatology [16-19]. Abuse experienced during childhood places adults at greater risk for the development of psychopathology, including PTSD [20].

Developmental theory suggests that the more pernicious effects of childhood trauma can be explained through a combination of factors. First, the nature of childhood abuse is such that it is typically protracted in nature whereas adults may be more likely to experience trauma confined to a single assault [21]. Secondly, because children have a relatively limited social network, perpetrators are likely to be intimate companions of the child such as a parent, stepparent, or sibling [22]. This betrayal often shatters fundamental interpersonal trust, which is highly problematic for future social development. Third, the situations are often intractable as children may be both dependent on these adults for their survival and lacking in resources to determine to bring such abuse to an end [22].

While trauma is nearly ubiquitous, PTSD is not. In fact, epidemiological estimates suggest that while $40-90 \%$ of adults will experience a Criterion A traumatic event in their lifetime, only $7 \%$ will develop PTSD [23]. Subsequently, much research has been devoted to understanding factors that predict or moderate this relationship. In the case of Latinos, one factor that is particularly salient is acculturation. Acculturation is the process of adaptation into a host culture [24]. Given that $36 \%$ of Latinos living in the USA are immigrants [25] and another 39\% are first-generation Americans [26], acculturation is a critical concept in research examining Latino functioning. While substantial attention has been devoted to the topic of acculturation, the findings are mixed. Some research has demonstrated that higher levels of acculturation (i.e., greater adoption of the USA cultural norms) led to negative physical and psychological health outcomes [27-35], while other studies have shown that lower levels of acculturation have deleterious health effects [36-40].

With specific regard to PTSD, mixed support was found for the effect of acculturation when comparing immigrant Latinos with their USA-born counterparts. To understand the significance of acculturation among Latinos, the acculturative stress theory suggests that the migration process involves cultural, social economic, and 
personal challenges and changes that influence mental health outcomes depending on the level of stress experiences [41]. Moreover, the acculturation process may affect protective factors of traditional Latino culture, such as close relationships with extended family members that may buffer the influences of stress and prevent the development of psychopathology [42]. Some researchers have found that Latinos low on acculturation to the USA "host" culture report more severe PTSD symptoms [43-45]. In contrast, other studies support the notion that higher levels of acculturation may serve as a risk factor for PTSD. For example, Williams et al., [46] reported increased odds of PTSD onset among USA-born Latinos relative to foreign-born Latinos following musculoskeletal injuries. Adding more complexity, another study found no significant effect of acculturation and PTSD among Latinos [47]. These studies demonstrated that acculturative factors might play an important role in shaping how Latinos respond to traumatic events; however, given the mixed results, further study is necessary to understand how acculturation relates to PTSD symptoms.

While many studies have suggested that when trauma occurs on the developmental continuum, it has much to do with the subsequent psychopathology that ensures, but few studies have provided direct comparisons of traumatic events in childhood versus adulthood. We hypothesized that individuals reporting their Worst Traumatic Event (WTE) in childhood would exhibit greater levels of PTSD symptomatology. We also predicted that the relationship between timing of the trauma and PTSD symptomatology would be moderated by acculturation where individuals who reported their WTE and had the lowest level of acculturation would report the highest number of PTSD symptoms.

\section{Methods}

\section{Study sample and design}

This study was part of a NIH funded study that examined Latinos use of substance abuse aftercare, called Oxford Houses. Oxford Houses are democratically self-run recovery homes in which same-sexed individuals live together to establish sobriety; they are the largest residential self-help recovery program in the USA $[48,49]$. After IRB approval was obtained, participants for this study were recruited from multiple community-based organizations and health facilities from a large metropolitan area in the Midwest. Inclusion criteria required that participants 1) were Latino and 2) had completed a substance abuse treatment program. Study recruitment was structured such that while Latino individuals were being introduced to Oxford Houses, they were also given information about this research study. Recruiters explained that participation in the study was entirely voluntary and that it did not exclude them from being assigned to an Oxford House. If interested, participants could indicate their interest by approaching the recruiter and giving informed consent by signing the consent form provided. Consent forms were provided in both Spanish and English. No Latino participant based on any individual characteristics, such as criminal justice involvement or legal status, was refused participation in this study. Although Substance Use Disorders (SUDs) were not the focus of this paper, the use of a formerly substance abusing population was a strong proxy population to study trauma as rates of trauma among substance abusing populations ranges between $30-58 \%$ [50-52]. At the time of this study, all participants had completed substance use treatment and, therefore, no one was using substances. Interviews were completed by bilingual research assistants and participants received $\$ 30$ after completing the interview [53].
This sample consisted of 104 Latinos (Table 1). The sample was predominately male ( $\mathrm{n}=87,82.9 \%)$. The mean age of participants was 37.1 years $($ Range $=18-63, \mathrm{SD}=10.5)$. In terms of the ethnic breakdown, 37.5\% $(\mathrm{n}=39)$ were Mexicans, $45.2 \%(\mathrm{n}=47)$ were Puerto Ricans and $17.3 \%(\mathrm{n}=18)$ were other (i.e., Cuban, Guatemalan, El Salvadorian). Of these 104, 27\% $(\mathrm{n}=29)$ self-reported that they were immigrants. The average time in the USA was 21.2 years $(\mathrm{SD}=14.0)$. The average score on the Psychological Acculturation Scale (PAS) [54] was 3.9 (i.e., 1.0-3.5, Latino; 3.6-6.5, bicultural; 6.6-9.0 American), signifying that the average participants was bicultural. The sample was highly traumatized with participants reporting an average of $9.6(\mathrm{SD}=14.0)$ Criterion A events.

\begin{tabular}{|c|c|c|c|}
\hline Variable & & M & SD \\
\hline Age & & 37.13 & 10.52 \\
\hline Education & & 11.45 & 2.03 \\
\hline \multirow[t]{2}{*}{ Time in US } & & 21.2 & 14 \\
\hline & & $\mathrm{n}$ & $\%$ \\
\hline \multicolumn{4}{|l|}{ Sex } \\
\hline & Male & 87 & 82.9 \\
\hline & Female & 13 & 17.1 \\
\hline \multicolumn{4}{|l|}{ Ethnicity } \\
\hline & Puerto Rican & 47 & 45.2 \\
\hline & Mexican & 39 & 37.5 \\
\hline & Other & 18 & 17.3 \\
\hline \multicolumn{4}{|c|}{ Acculturation Status } \\
\hline & Latino & 44 & 42.3 \\
\hline & Bicultural & 51 & 49 \\
\hline & American & 9 & 8.7 \\
\hline \multicolumn{4}{|l|}{ Employment } \\
\hline & Full-time (35+ hours per week) & 38 & 36.5 \\
\hline & Part-time (regular hours) & 13 & 12.5 \\
\hline & Part-time (irregular hours) & 21 & 20.2 \\
\hline & Unemployed & 20 & 19.2 \\
\hline & Other & 11 & 10.6 \\
\hline
\end{tabular}

Table 1: Sociodemographic Characteristics of the Patient Sample.

\section{Measures}

Only Section E of the Diagnostic Interview Schedule-IV (DIS) [55], which is based upon the diagnostic and statistical manual of mental disorders, fourth edition [56] was used to assess participants' PTSD symptoms as well as the nature and number of Criterion A events experienced. The first and second hypotheses were predicated on the DSM-IV-TR's conceptualization of PTSD. Participants who endorsed experiencing multiple traumatic events, were asked to nominate a WTE and to say at what age this event occurred. Examples of WTEs included sexual assaults, incest, physical abuse, and sudden death of friend/family member. The DIS was used because non-clinicians (i.e., research assistants) are able to administer this measure to participants. The PTSD section of the current version of the DIS was tested for reliability and validity in a study of substance abusers and had fair to good inter-rater reliability (kappa .40 - .67). The results are consistent with the literature on reliability of PTSD with substance abusers. While an English version of the DIS-IV was available, there was no published or commonly used Spanish version. 
A team of translators worked to translate and back-translate the DIS. The translators were native Spanish speakers from Spanish-speaking locales that were appropriate for the study's participants in Chicago (e.g., Mexico, Puerto Rico). Furthermore, the Spanish version was piloted on Latinos with SUDs and was implemented clearly and effectively.

Acculturation was measured with the Psychological Acculturation Scale (PAS) [54]. The PAS is a 10-item, 9-point Likert-type scale ( $1=$ only with Latinos to $9=$ only with Anglos) self-report measure that assesses sense of attachment to and belonging within the USA and Hispanic/Latino cultures. An item sample includes "with what group of people do you feel you share most of our beliefs and values?" A mean total score is derived from the scale, where a score of 5 indicates bicultural orientation. Both the English and Spanish versions of the PAS have good internal consistency $(\alpha=.90$ and .83$)$ and correlate with language and cultural preferences, along with percentage of life spent in the USA and measures of cultural values [57].

\section{Results}

To ensure that individuals reporting WTE in childhood simply had not accrued more Criterion A events given that their trauma histories potentially began at an earlier age, differences in number of traumas between individuals reporting WTE in childhood and those reporting in adulthood were examined, and no significant differences were found $(\mathrm{b}=1.79, \mathrm{SE}=2.80, \mathrm{t}=.64, \mathrm{p}=.52)$. To test if acculturation was a true moderator of the relationship between timing of the trauma and PTSD symptoms, the potential confound of a significant relationship between timing of the trauma and acculturation was examined; this potential confound was ruled out $(\mathrm{b}=0.22, \mathrm{SE}=0.35, \mathrm{t}=0.63, \mathrm{p}=.53)$.

To analyze the main hypotheses, a multiple regression analysis was conducted. Because of the relatively smalls sample size (i.e., 104 participants), data were bootstrapped to 5000 samples with a $95 \%$ confidence interval. For the first hypothesis, there was a significant relationship between timing of trauma such that participants who experienced their self-identified most traumatic event in childhood (i.e., before 18 years of age) exhibited greater levels of PTSD symptomatology than those who experienced their self-identified WTE in adulthood $(\mathrm{b}=6.52,95 \% \mathrm{CI}=2.91-9.79, \mathrm{SE}=1.80, \mathrm{p}=.001)$. Acculturation was not a significant predictor of PTSD symptomology $(\mathrm{b}=0.58,95 \% \mathrm{CI}=-0.09-1.20, \mathrm{SE}=0.32, \mathrm{t}=1.80, \mathrm{p}=.08)$.

We explored the moderating effect of acculturation on the relationship between timing of the trauma and PTSD symptoms. There was a significant moderation effect $(b=-1.06, \mathrm{SE}=0.49$, $\mathrm{t}=-2.18, \mathrm{p}=.03, \mathrm{CI}=-1.95-0.15)$. The simple slopes of acculturation were examined. For those reporting WTE in childhood, the slope of acculturation was negative and not significant, $(b=-0.48, S E=0.37$, $\mathrm{t}=-1.32, \mathrm{p}=.19, \mathrm{CI}=-1.21-0.24)$. For adults, the slope of acculturation was positive and not significant $(b=0.58, \mathrm{SE}=0.32$, $\mathrm{t}=1.80, \mathrm{p}=.08 \mathrm{CI}=-.06-1.22$; see figure 1 ).

Three simple slopes analyses were performed, fixing acculturation levels at the mean, one standard deviation below the mean, and one standard deviation above the mean [58]. For participants scoring average on PAS, the average difference in PTSD symptomology between those with childhood vs. adult trauma was 2.42 symptoms $(95 \% \mathrm{CI}=0.73-4.12, \mathrm{SE}=.85, \mathrm{t}=2.83, \mathrm{p}<.01)$. Simple slopes analyses indicated that for participants one standard deviation below

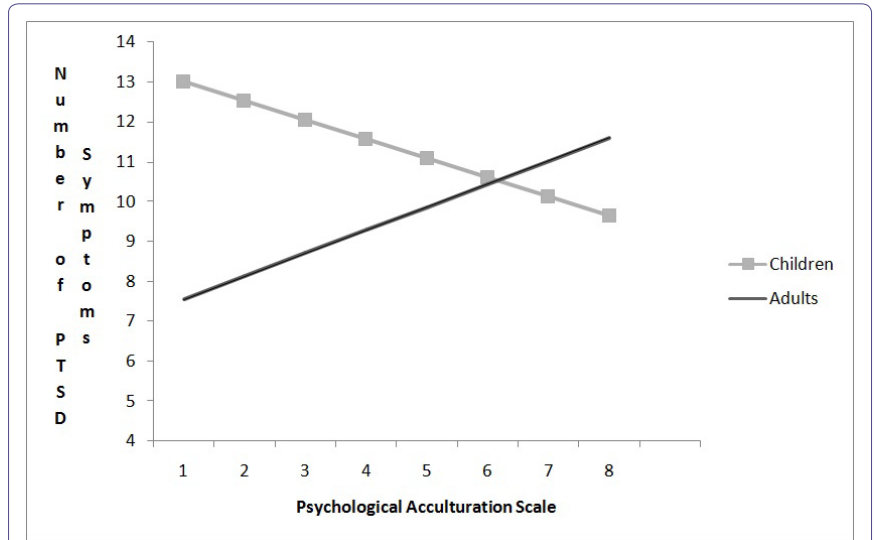

Figure 1: Interaction of Acculturation and Timing of Trauma (Child versus Adult) on Symptoms.

the mean on PAS (i.e., PAS score of 2.09), the average difference in PTSD symptomatology between those reporting child trauma as their WTE and those reporting adult trauma as their WTE was significantly different such that those reporting WTE in childhood had more PTSD symptoms $(\mathrm{b}=4.30,95 \% \mathrm{CI}=1.87-6.72, \mathrm{SE}=1.22, \mathrm{t}=3.52, \mathrm{p}<.01)$. However, at one standard deviation above the mean (i.e., PAS score of 5.63), there was no significant difference between child WTE and adult WTE in terms of PTSD symptoms $(\mathrm{b}=0.55,95 \%$ $\mathrm{CI}=-1.84-2.94, \mathrm{SE}=1.20, \mathrm{t}=0.46, \mathrm{p}=.65$; see figure 2 ). $\mathrm{A}$ Johnson-Neyman technique was used in order to examine how far apart on acculturation participants needed to be in order for there to be a difference in the effect of trauma on symptomology. Hayes's PROCESS (2013) was used to examine the Johnson-Neyman significance regions; when acculturation score on the PAS was less than 4.47 , the group with childhood and non-childhood traumas differed on symptomology.

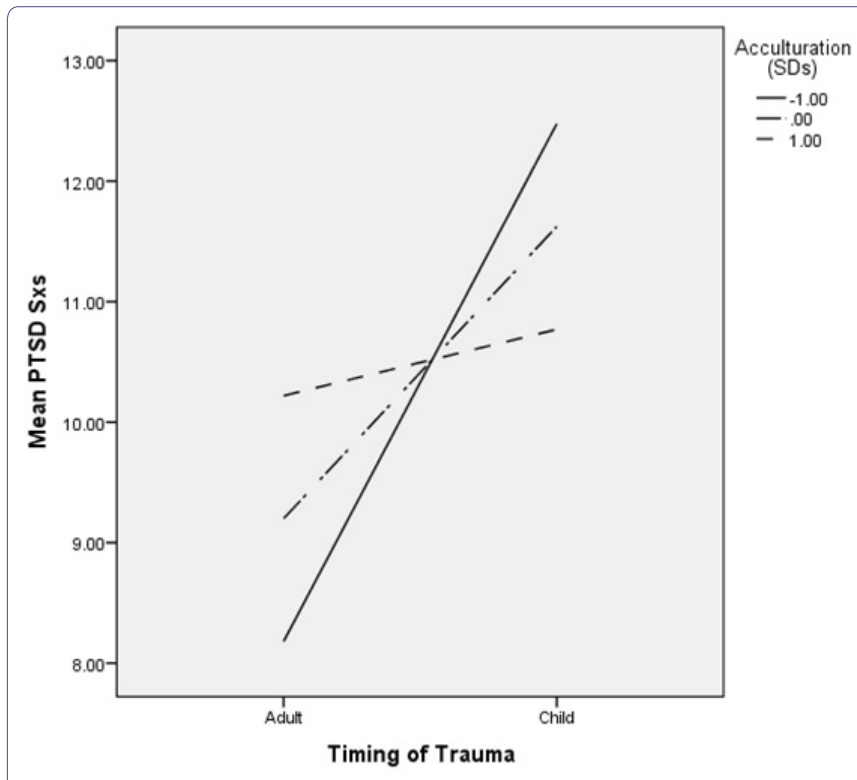

Figure 2: The Impact of Timing of Trauma (Child versus Adult) on Three Levels of Acculturation.

Acculturation (SDs) refer to three simple slopes analyses, fixing acculturation levels at the mean (0), one standard deviation below the mean $(-1)$, and one standard deviation above the mean (+1).

Mean PTSD Sxs refers to PTSD symptomology

Two further simple slopes analyses of acculturation were examined, to further examine the interaction effect. For those 
reporting WTE in childhood, the slope of acculturation was negative and not significant, $(b=-0.48,95 \% \mathrm{CI}=-1.21-0.24, \mathrm{SE}=0.37$, $\mathrm{t}=-1.32, \mathrm{p}=.19)$. For adults, the slope of acculturation was positive and not significant $(b=0.58,95 \% \mathrm{CI}=-.06-1.22, \mathrm{SE}=0.32, \mathrm{t}=1.80$, $\mathrm{p}=.08)$.

\section{Discussion}

Findings from this study indicated that individuals who reported their worst traumatic event occurred in childhood had greater PTSD symptomatology than individuals reporting their WTE in adulthood. Our study is one of the few studies to provide a direct comparison of child versus adult trauma in terms of PTSD symptomatology. Our finding-that child trauma leads to worse symptomatology than adult trauma-is consistent with findings in neurobiology that stress experienced during periods of rapid brain development can lead to worse symptomatology [59].

The other main finding relates to acculturation. In the present study we found that the moderation effect of acculturation depends on the timing of the WTE with the influence of acculturation different for individuals reporting their WTE in childhood. Specifically, those who reported their WTE in childhood and had the lowest level of acculturation reported the highest number of PTSD symptoms. There was no significant effect for those reporting their WTE in adulthood.

Acculturation is a multifaceted and dynamic phenomenon. On one side, acculturation has been linked to the erosion of core institutions of social cohesion, like culture and family systems [37,60]; and on the other side, higher levels of acculturation have been linked to greater help-seeking behaviors [61,62], fewer barriers to care [63-65] and more resources [66].

In the present study, it was individuals who reported the lowest level of acculturation and their WTE in childhood who were at greatest risk for PTSD. One plausible explanation for this scenario may be that individuals who experienced trauma as children and were not acculturated to USA cultural norms had the least opportunity to seek the services that would lead to the attenuation of trauma symptoms. Moreover, if the child is unacculturated, it is likely that the family has similarly low levels of acculturation, subsequently rendering them less likely to access appropriate services. Thus, a low acculturated family might be less able to seek services for their traumatized child. Additionally, given that that child trauma is most often perpetrated within the context of a family system $[21,22]$, this raises questions about whether the very system responsible for the abuse would be the most likely source of its remediation. Thus, instead of the child's family reporting the abuse, it may be that children reach outside of the family to disclose (e.g., teacher, counselor), which may lead to intervention. It may also be that more acculturated children-who are more comfortable within the system, have more frequent contacts with individuals outside of their family and have greater command of English-are more likely to either be noticed by or confide in an adult. In summary, more acculturated children may more easily navigate the social structures that would permit disclosure, facilitate intervention and, subsequently, lead to lower PTSD symptomatology.

Another explanation that may elucidate the relationship between child trauma, low acculturation, and PTSD symptomatology draws from work on the effects of cumulative stress [67-69]. Converging research from both behavioral and neurobiological studies demonstrates the idea that increasing cumulative exposure to stressful events leads to greater psychopathology and neurobiological changes.
In terms of psychopathology, cumulative adversity and repeated exposure to stressful life events are known to increase risk of mood and anxiety disorders [70-75] and addictive disorders [69-73]. Likewise, a recent study by Ansell and colleagues found that cumulative stress was related to smaller gray matter volume in prefrontal and limbic regions involved in stress, emotion and reward regulation and impulse control [76].

Acculturation in the context of Latinos living in the USA is inherently predicated on the immigration process. This notion of cumulative stress applies to the immigration and acculturation processes because substantial research supports the idea that immigration and the subsequent acculturation processes are highly stressful [24,77-80]. Low acculturated families often contend with stressors related to economic, linguistic, and cultural barriers [81-83].

These chronic and unremitting stressors may accumulate in insidious ways-both directly and indirectly-and foster the development of psychopathology. First, if a child has been traumatized and lives within a larger social ecology that is chaotic and stressful, the child may experience the cumulative effects of both the trauma and the larger social context. Second, the reaction of the family, namely the parents, has been shown to be a more powerful predictor of the child's subsequent symptom development than the abuse-related factors [84-89]. For the lowly acculturated parents who are also living in a high-stress environment, they may be unable to respond to the child appropriately to both attenuate the effects of the trauma and teach appropriate coping methods (e.g., self-soothing). If these individuals, traumatized as children, did not receive appropriate intervention for PTSD related symptoms, it is unlikely that these symptoms would have spontaneously remitted [90-92]. Thus, it is quite plausible that the participants of the current study, though adults, may have chronic PTSD related to trauma(s) in childhood.

In terms of individual who reported their worst traumatic event occurred during adulthood, they had lower PTSD symptomatology. Earlier research has supported the notion that adult trauma is less pernicious because adults have developed more efficacious coping strategies and have better access to resources to deal with the overwhelming event $[18,19]$. Thus, regardless of acculturative status, individuals who reported their WTE as adults may have been better equipped to deal with sequelae of the WTE.

A limitation of this study included its cross-sectional design. Therefore, the temporal ordering of acculturation processes and trauma cannot be established. Relatedly, the measures were all given to adult participants who were asked to recall their WTE and then attribute symptoms to an event that, in some cases, occurred decades ago. This issue of retrospective recall bias is one that is well documented [93] and beleaguers the entire set of cross-sectional trauma literature. Future studies that examine trauma and acculturation with a longitudinal design may do much to assist in understanding more about the temporal ordering of these phenomena and may even elucidate the most effective time to intervene. Another limitation deals with issues related to trauma typology. While we collected data on the timing of when the WTE occurred, we did not investigate the trauma typology. Future work that looks at the intersection of trauma typology and timing of WTE would enrich understanding of trauma and its sequelae. Also, while an English version of the DIS-IV was available, there was no published Spanish version; therefore, there are no psychometric properties. Our study 
Citation: DiGangi JA, Goddard AJ, Miller SA, Leon G, Jason LA (2016) Differences in PTSD Symptomatology Among Latinos with Childhood and Adult Trauma: The Moderating Effect of Acculturation. J Addict Addictv Disord 3: 009.

represents the first time the DIS-IV was used in Spanish, a team of native Spanish speakers worked to translate and back-translate the instrument. Another limitation was that ethnicity was not directly tested in this study by comparing to another group. Finally, the nature of the study's sample hinders generalizability. Although trauma and SUDs are highly comorbid, the fact that this was a treatment-seeking population limits the generalizability of its conclusions. Future work that seeks to replicate these findings with non-substance abusing populations would help clarify the broader relationship that trauma shares with symptomatology and acculturation. Similarly, future work that explores how PTSD symptoms may manifest differently in samples with and without substance abuse histories would do much to enhance our understanding of both the course and treatment of PTSD.

Implications from the current study suggest that individuals with child trauma and low acculturation may be at risk for psychopathology. Interventions that target these especially vulnerable individuals, particularly during childhood, in ways that promote cultural sensitivity and inclusion may do well to attenuate PTSD and other disorders. However, it is important to note that interventions that target only the trauma may be missing the larger social ecology in which these individuals live. Low acculturation is linked to a host of social and economic stressors. The effects of high-stress, chaotic environments in which cumulative stress accrues may have more to do with subsequent symptomatology than the trauma itself [94]. At present, there is only limited research that looks at the effects of cumulative stress on humans [76]. Thus, future work that examines the causes and effects of cumulative stress will do much to facilitate the treatment of mental disorders and the prevention of the circumstances that cause them. Additionally, the full ramifications of acculturation are not yet understood. More work is needed to precisely delineate when acculturation is a risk factor and when it's protective. Likewise, research that elucidates how interventions can accentuate the benefits of acculturation while attenuating its adverse effects may be of use in designing appropriate interventions.

\section{Acknowledgment}

The authors appreciate the financial support from the National Institute on Alcohol Abuse and Alcoholism (NIAAA grant numbers AA12218 and AA16973).

\section{References}

1. Bowen DJ, Carscadden L, Beighle K, Fleming I (1992) Post-traumatic stress disorder among Salvadoran women: Empirical evidence and description of treatment. Women \& Therapy 13: 267-280.

2. Feder A, Ahmad S, Lee EJ, Morgan JE, Singh R, et al. (2012) Coping and PTSD symptoms in Pakistani earthquake survivors: Purpose in life, religious coping and social support. J Affect Disord 147: 156-163.

3. Goto T, Wilson JP (2003) A review of the history of traumatic stress studies in Japan: from traumatic neurosis to PTSD. Trauma Violence Abuse 4: 195-209.

4. Hobfoll SE, Canetti-Nisim D, Johnson RJ, Palmieri PA, Varley JD, et al. (2008) The association of exposure, risk, and resiliency factors with PTSD among Jews and Arabs exposed to repeated acts of terrorism in Israel. J Trauma Stress 21: 9-21.

5. Kolassa IT, Ertl V, Eckart C, Glöckner F, Kolassa S, et al. (2010) Association study of trauma load and SLC6A4 promoter polymorphism in posttraumatic stress disorder: evidence from survivors of the Rwandan genocide. $\mathrm{J}$ Clin Psychiatry 71: 543-547.

6. Caetano R, Ramisetty-Mikler S, Field CA (2005) Unidirectional and bidirectional intimate partner violence among White, Black, and Hispanic couples in the United States. Violence Vict 20: 393-406.
7. Cervantes RC, Salgado de Snyder VN, Padilla AM (1989) Posttraumatic stress in immigrants from Central America and Mexico. Hosp Community Psychiatry 40: 615-619.

8. Eisenman DP, Gelberg L, Liu H, Shapiro MF (2003) Mental health and health-related quality of life among adult Latino primary care patients living in the United States with previous exposure to political violence. JAMA 290: 627-634.

9. Holman EA, Silver RC, Waitzkin H (2000) Traumatic life events in primary care patients: a study in an ethnically diverse sample. Arch Fam Med 9: 802810.

10. Galea S, Vlahov D, Tracy M, Hoover DR, Resnick H, et al. (2004) Hispanic ethnicity and post-traumatic stress disorder after a disaster: evidence from a general population survey after September 11, 2001. Ann Epidemiol 14: 520-531.

11. Ortega AN, Rosenheck R (2000) Posttraumatic stress disorder among Hispanic Vietnam veterans. Am J Psychiatry 157: 615-619.

12. Ruef AM, Litz BT, Schlenger WE (2000) Hispanic ethnicity and risk for combat-related posttraumatic stress disorder. Cultur Divers Ethnic Minor Psychol 6: 235-251.

13. Pole N, Best SR, Weiss DS, Metzler T, Liberman AM, et al. (2001) Effects of gender and ethnicity on duty-related posttraumatic stress symptoms among urban police officers. J Nerv Ment Dis 189: 442-448.

14. Kessler RC, Sonnega A, Bromet E, Hughes M, Nelson CB (1995) Posttraumatic stress disorder in the National Comorbidity Survey. Arch Gen Psychiatry 52: 1048-1060.

15. Fontana A, Rosenheck R (1994) Posttraumatic stress disorder among Vietnam Theater Veterans. A causal model of etiology in a community sample. J Nerv Ment Dis 182: 677-684.

16. Burnam MA, Stein JA, Golding JM, Siegel JM, Sorenson SB, et al. (1988) Sexual assault and mental disorders in a community population. $J$ Consult Clin Psychol 56: 843-850.

17. McCauley J, Kern DE, Kolodner K, Dill L, Schroeder AF, et al. (1997) Clinical characteristics of women with a history of childhood abuse: unhealed wounds. JAMA 277: 1362-1368.

18. van der Kolk BA, Pelcovitz D, Roth S, Mandel FS, McFarlane A, et al. (1996) Dissociation, somatization, and affect dysregulation: the complexity of adaptation of trauma. Am J Psychiatry 153: 83-93.

19. Waldrop AE, Ana EJ, Saladin ME, McRae AL, Brady KT (2007) Differences in early onset alcohol use and heavy drinking among persons with childhood and adulthood trauma. Am J Addict 16: 439-442.

20. Breslau N, Davis GC, Andreski P (1995) Risk factors for PTSD-related traumatic events: a prospective analysis. Am J Psychiatry 152: 529-535.

21. Cloitre M, Stolbach BC, Herman JL, van der Kolk B, Pynoos R, et al. (2009) A developmental approach to complex PTSD: childhood and adult cumulative trauma as predictors of symptom complexity. J Trauma Stress 22: 399-408.

22. Ronnie Janoff-Bulman (1992) Shattered Assumptions: Towards a New Psychology of Trauma. Free Press, New York, USA.

23. Kessler RC, Chiu WT, Demler O, Merikangas KR, Walters EE (2005) Prevalence, severity, and comorbidity of 12-month DSM-IV disorders in the National Comorbidity Survey Replication. Arch Gen Psychiatry 62: 617-627.

24. Mena FJ, Padilla AM, Maldonado M (1987) Acculturative stress and specific coping strategies among immigrant and later generation college students. Hispanic Journal of Behavioral Sciences 9: 207-225.

25. Motel S, Patten E (2013) Statistical portrait of Hispanics in the United States, 2011. Pew Research Center, Washington, DC, USA.

26. Pew Research Center (2013) Second-Generation Americans - A portrait of the Adult Children of Immigrants. Pew Research Center, Washington, DC, USA. 
Citation: DiGangi JA, Goddard AJ, Miller SA, Leon G, Jason LA (2016) Differences in PTSD Symptomatology Among Latinos with Childhood and Adult Trauma: The Moderating Effect of Acculturation. J Addict Addictv Disord 3: 009.

27. Acevedo MC (2000) The role of acculturation in explaining ethnic differences in the prenatal health-risk behaviors, mental health and parenting beliefs of Mexican American and European American at-risk women. Child Abuse Negl 24: 111-127.

28. Coonrod DV, Bay RC, Balcazar H (2004) Ethnicity, acculturation and obstetric outcomes. Different risk factor profiles in low- and high-acculturation Hispanics and in white non-Hispanics. J Reprod Med 49: 17-22.

29. Espino DV, Maldonado D (1990) Hypertension and acculturation in elderly Mexican Americans: results from 1982-84 Hispanic HANES. J Gerontol 45: 209-213.

30. Gordon-Larsen P, Harris KM, Ward DS, Popkin BM, National Longitudinal Study of Adolescent Health (2003) Acculturation and overweight-related behaviors among Hispanic immigrants to the US: The National Longitudinal Study of Adolescent Health. Soc Sci Med 57: 2023-2034.

31. Ortega AN, Rosenheck R, Alegría M, Desai RA (2000) Acculturation and the lifetime risk of psychiatric and substance use disorders among Hispanics. J Nerv Ment Dis 188: 728-735.

32. Popkin BM, Udry JR (1998) Adolescent obesity increases significantly in second and third generation U.S. immigrants: The National Longitudinal Study of Adolescent Health. J Nutr 128: 701-706.

33. Stern MP, Gonzalez C, Mitchell BD, Villalpando E, Haffner SM, et al. (1992) Genetic and environmental determinants of type II diabetes in Mexico City and San Antonio. Diabetes 41: 484-492.

34. Vega WA, Sribney WM, Achara-Abrahams I (2003) Co-occurring alcohol, drug, and other psychiatric disorders among Mexican-origin people in the United States. Am J Public Health 93: 1057-1064.

35. West SK, Munoz B, Klein R, Broman AT, Sanchez R, et al. (2002) Risk factors for Type II diabetes and diabetic retinopathy in a mexican-american population: Proyecto VER. Am J Ophthalmol 134: 390-398.

36. Escobar JI, Burnam A, Karno M, Forsythe A, Landsverk J, et al. (1986) Use of the Mini-Mental State Examination (MMSE) in a community population of mixed ethnicity. Cultural and linguistic artifacts. J Nerv Ment Dis 174: 607614.

37. Miranda AO, Estrada D, Firpo-Jimenez M (2000) Differences in family cohesion, adaptability, and environment among Latino families in dissimilar stages of acculturation. The Family Journal 8: 341-350.

38. Rogler LH, Cortes DE, Malgady RG (1991) Acculturation and mental health status among Hispanics. Convergence and new directions for research. Am Psychol 46: 585-597.

39. Szapocznik J, Kurtines W (1980) Acculturation, biculturalism and adjustmen among Cuban Americans. In: Padilla A (ed.). Acculturation, theory, models, and some new findings. Westview Press, American Association for the Advancement of Science, USA. Pg no: 139-159.

40. Torres-Matrullo C (1976) Acculturation and psychopathology among Puerto Rican women in mainland United States. Am J Orthopsychiatry 46: 710-719.

41. Conway KP, Swendsen JD, Dierker L, Canino G, Merikangas KR (2007) Psychiatric comorbidity and acculturation stress among Puerto Rican substance abusers. Am J Prev Med 32: 219-225.

42. De La Rosa M (2002) Acculturation and Latino adolescents' substance use: a research agenda for the future. Subst Use Misuse 37: 429-456.

43. Escobar JI, Randolph ET, Puente G, Spiwak F, Asamen JK, et al. (1983) Post-traumatic stress disorder in Hispanic Vietnam veterans. Clinical phenomenology and sociocultural characteristics. J Nerv Ment Dis 171: 585-596.

44. Marshall GN, Orlando M (2002) Acculturation and peritraumatic dissociation in young adult Latino survivors of community violence. J Abnorm Psychol 111: $166-174$

45. Perilla JL, Norris FH, Lavizzo EA (2002) Ethnicity, culture, and disaster response: Identifying and explaining ethnic differences in PTSD six month after Hurricane Andrew. Journal of Social and Clinical Psychology 21: 20-45.
46. Williams AE, Smith WR, Starr AJ, Webster DC, Martinez RJ, et al. (2008) Ethnic differences in posttraumatic stress disorder after musculoskeletal trauma. J Trauma 65: 1054-1065.

47. Ortega AN, Rosenheck R (2001) Mental and physical health and acculturation among Hispanic Vietnam Veterans. Mil Med 166: 894-897.

48. Jason LA, Ferrari JR (2010) Oxford House Recovery Homes: Characteristics and Effectiveness. Psychol Serv 7: 92-102.

49. Jason LA, Olson BD, Foli K (2008) Rescued Lives: The Oxford House Approach to Substance Abuse. Routledge, New York, USA.

50. Brown PJ, Recupero PR, Stout R (1995) PTSD substance abuse comorbidity and treatment utilization. Addict Behav 20: 251-254.

51. Bremner JD, Southwick SM, Darnell A, Charney DS (1996) Chronic PTSD in Vietnam combat veterans: course of illness and substance abuse. Am J Psychiatry 153: 369-375.

52. Back S, Dansky BS, Coffey SF, Saladin ME, Sonne S, et al. (2000) Cocaine dependence with and without post-traumatic stress disorder: a comparison of substance use, trauma history and psychiatric comorbidity. Am J Addict 9: 51-62.

53. Jason LA, Digangi JA, Alvarez J, Contreras R, Lopez-Tamayo R, et al. (2013) Evaluating a bilingual voluntary community-based healthcare organization. J Ethn Subst Abuse 12: 321-338.

54. Tropp LR, Erkut S, Coll CG, Alarcón O, Vázquez García HA (1999) Psychological acculturation: development of a new measure for Puerto Ricans on the U.S. Mainland. Educ Psychol Meas 59: 351-367.

55. Robins LN, Cottler, LB, Bucholz, KK, Compton W (1995) Diagnostic Interview Schedule for DSM-IV (DIS-IV). School of Medicine, Department of Psychiatry, Washington University, St. Louis, Missouri, USA.

56. American Psychiatric Association, Task Force on DSM-IV (1994) Diagnostic and statistical manual of mental disorders: DSM-IV. (4thedn), American Psychiatric Association, Washington, DC, USA.

57. Ghorpade J, Lackritz J, Singh G (2004) Psychological acculturation of ethnic minorities into White Anglo American culture: Consequences and predictors. Journal of Applied Social Psychology 34: 1208-1228.

58. Aiken LS, West SG, Reno RR (1991) Multiple regression: Testing and interpreting interactions. SAGE Publications, Thousand Oaks, CA, USA.

59. Gunnar M, Quevedo K (2007) The neurobiology of stress and development. Annu Rev Psychol 58: 145-173.

60. Vega WA, Kolody B, Valle JR (1986) The relationship of marital status, confidant support, and depression among Mexican immigrant women. Journal of Marriage and the Family 48: 597-605.

61. Hu DJ, Covell RM (1986) Health care usage by Hispanic outpatients as function of primary language. West J Med 144: 490-493.

62. Marks G, Garcia M, Solis JM (1990) Health risk behaviors of Hispanics in the United States: findings from HHANES, 1982-84. Am J Public Health 80: 20-26.

63. Chesney AP, Chavira JA, Hall RP, Gary HE Jr (1982) Barriers to medical care of Mexican-Americans: the role of social class, acculturation, and social isolation. Med Care 20: 883-891.

64. Clark L (2002) Mexican-origin mothers' experiences using children's health care services. West J Nurs Res 24: 159-179.

65. Wells KB, Golding JM, Hough RL, Burnam MA, Karno M (1989) Acculturation and the probability of use of health services by Mexican Americans. Health Serv Res 24: 237-257.

66. Thamer M, Richard C, Casebeer AW, Ray NF (1997) Health insurance coverage among foreign-born US residents: the impact of race, ethnicity, and length of residence. Am J Public Health 87: 96-102.

67. Dube SR, Felitti VJ, Dong M, Giles WH, Anda RF (2003) The impact of ad verse childhood experiences on health problems: Evidence from four birth cohorts dating back to 1900. Prev Med 37: 268-277. 
Citation: DiGangi JA, Goddard AJ, Miller SA, Leon G, Jason LA (2016) Differences in PTSD Symptomatology Among Latinos with Childhood and Adult Trauma: The Moderating Effect of Acculturation. J Addict Addictv Disord 3: 009.

68. Turrell G, Lynch JW, Leite C, Raghunathan T, Kaplan GA (2007) Socioeconomic disadvantage in childhood and across the life course and all-cause mortality and physical function in adulthood: evidence from the Alameda County Study. J Epidemiol Community Health 61: 723-730.

69. Sinha R (2008) Chronic stress, drug use, and vulnerability to addiction. Ann NY Acad Sci 1141: 105-130.

70. Caspi A, Sugden K, Moffitt TE, Taylor A, Craig IW, et al. (2003) Influence of life stress on depression: moderation by a polymorphism in the 5-HTT gene. Science 301: 386-389.

71. Turner RJ, Lloyd DA (1999) The stress process and the social distribution of depression. J Health Soc Behav 40: 374-404.

72. Lloyd DA, Turner RJ (2008) Cumulative lifetime adversities and alcohol dependence in adolescence and young adulthood. Drug Alcohol Depend 93: 217-226.

73. Turner RJ, Lloyd DA (2003) Cumulative adversity and drug dependence in young adults: racial/ethnic contrasts. Addiction 98: 305-315.

74. Cohen S, Kessler RC, Gordon LU (1995) Checklist measurement of stressful life events. In: Cohen S, Kessler R, Underwood GL (eds.). Measuring Stress. Oxford University Press, New York, USA. Pg no: 29-58.

75. Wheaton B, Young M, Montazer S, Stuart-Lahman K (1999) Social stress in the Twenty-First Century. In: Aneshensel CS, Phelan JC, Bierman A (eds.) Handbook of the Sociology of Mental Health. (2ndedn), Plenum Publishing, New York, USA Pg no: 277-300.

76. Ansell EB, Rando K, Tuit K, Guarnaccia J, Sinha R (2012) Cumulative adversity and smaller gray matter volume in medial prefrontal, anterior cingulate, and insula regions. Biol Psychiatry 72: 57-64.

77. Bernal G, Sáez-Santiago E (2006) Culturally centered psychosocial interventions. Journal of Community Psychology 34: 121-132.

78. Cervantes RC, Castro FG (1985) Stress, coping, and Mexican American mental health: A systematic review. Hispanic Journal of Behavioral Sciences 7: 1-73.

79. Escobar JI, Hoyos Nervi C, Gara MA (2000) Immigration and mental health: Mexican Americans in the United States. Harv Rev Psychiatry 8: 64-72.

80. Ko S (2005) Promoting Culturally Competent Trauma-Informed Practices. NCTN Culture \& Trauma Brief, The National Child Traumatic Stress Network, Los Angeles, CA, USA.

81. Córdova Jr D, Cervantes RC (2010) Intergroup and within-group perceived discrimination among U.S.-born and foreign-born Latino youth. Hispanic Journal of Behavioral Sciences 32: 259-274.
82. Rice FP, Dolgin KG (2002) The Adolescent: Development, Relationships, and Culture. (12thedn), Allyn and Bacon, Boston, USA.

83. Suárez-Orozco C, Suárez-Orozco MM (2001) Children of immigration. Harvard University Press, USA.

84. Burgess AW, Hartman CR, Kelley SJ, Grant CA, Gray EB (1990) Parental response to child sexual abuse trials involving day care settings. Journal of Traumatic Stress 3: 395-405.

85. Carlson EB, Dalenberg C, Armstrong J, Daniels JW, Loewenstein R, et al. (2001) Multivariate prediction of posttraumatic symptoms in psychiatric inpatients. J Trauma Stress 14: 549-567.

86. Lauterbach D, Koch EI, Porter K (2007) The relationship between childhood support and later emergence of PTSD. J Trauma Stress 20: 857-867.

87. Morrison NC, Clavenna-Valleroy J (1998) Perceptions of maternal support as related to self-concept and self-report of depression in sexually abused female adolescents. Journal of Child Sexual Abuse 7: 23-40.

88. Tjersland O, Mossige S, Gulbrandsen W, Jensen TK, Reichelt S (2006) Helping families when child sexual abuse is suspected but not proven. Child \& Family Social Work 11: 297-306.

89. Tremblay C, Hébert M, Piché C (1999) Coping strategies and social support as mediators of consequences in child sexual abuse victims. Child Abuse Negl 23: 929-945.

90. Bomyea J, Lang AJ (2012) Emerging interventions for PTSD: future directions for clinical care and research. Neuropharmacology 62: 607-616.

91. Cloitre M, Courtois CA, Charuvastra A, Carapezza R, Stolbach BC, et al (2011) Treatment of complex PTSD: results of the ISTSS expert clinician survey on best practices. J Trauma Stress 24: 615-627.

92. Walter KH, Palmieri PA, Gunstad J (2010) More than symptom reduction: changes in executive function over the course of PTSD treatment. J Trauma Stress 23: 292-295.

93. Southwick SM, Morgan CA 3rd, Nicolaou AL, Charney DS (1997) Consistency of memory for combat-related traumatic events in veterans of Operation Desert Storm. Am J Psychiatry 154: 173-177.

94. Turner RJ, Lloyd DA (1995) Lifetime traumas and mental health: the significance of cumulative adversity. J Health Soc Behav 36: 360-376. 